\title{
Phytochemical and Biological Progress of Cynanchum paniculatum
}

\author{
Liangyan Liu ${ }^{a}$ and Chang-An Geng ${ }^{*, b}$ \\ ${ }^{a}$ College of Agrnomyand Biotechnology, Yunnan Agriculture University, Kunming 650201, China \\ ${ }^{b}$ State Key Laboratory of Phytochemistry and Plant Resources in West China, Kunming Institute of Botany, \\ Chinese Academy of Sciences, Kunming, Yunnan 650201, China
}

Email: gengchangan@mail.kib.ac.cn (C. G.)

\begin{abstract}
Cynanchum paniculatum (Xuchangqing) is a famous traditional Chinese herb (TCH) widely used for treating rheumatism and pains in China. $\mathrm{C}_{21}$ steroids and acetophenones are the characteristic constituents in this $\mathrm{TCH}$, from which a total of 61 compounds have been reported involving $32 \mathrm{C}_{21}$ steroids, 13 phenols, seven triterpenoids and nine other compounds. Biological investigation on this herb revealed the anti-inflammatory, anti-snake venom, anti-microbial, neuroprotective and anti-cancer properties of the pure compounds or crude extracts. This minireview summarized the phytochemical and biological progress of $C$. paniculatum to provide a reference for better understanding the effective substances of Xuchangqing.
\end{abstract}

Keywords Cynanchum paniculatum, Xuchangqing, $\mathrm{C}_{21}$ steroids, acetophenones, anti-inflammatory activity

\section{Introduction}

Cynanchum containing about 200 species is a large genus in the family Asclepiadaceae, which is mainly distributed in east Africa, the Mediterranean regions, and the tropical, subtropical and temperate areas of Europe and Asia. There are 53 species and 12 varieties in China, many of which are famous traditional Chinese herbs (TCHs), e.g., Cynanchum paniculatum (Xuchangqing), Cynanchum bungei (Baishouwu), Cynanchum glaucescens (Baiqian) and Cynanchum atratum (Baiwei). C. paniculatum is a perennial plant mainly distributed in China, Japan and Korea. In the traditional Chinese medicine (TCM) theory, its dried root and rhizome are recorded as the raw material of Xuchangqing, which is a well-known TCM for the treatment of rheumatic arthralgia, stomachache, toothache, lumbago, traumatic injuries, urticaria and eczema. ${ }^{[1]}$ Many formulae (e.g., Zhenggu Water, Xiaozhongzhitong Tincture, Guci Pill, Fengshiding Capsule,) with Xuchangqing as the active composition are renowned for the protective effects on rheumatism, edema and pain. Modern phytochemical and pharmacological investigation revealed the anti-inflammatory, anti-snake venom, anti-microbial, neuroprotective and anti-cancer properties of $C$. paniculatum with $\mathrm{C}_{21}$ steroids and acetophenones as the mainly active constituents. ${ }^{[2,3]} \mathrm{Up}$ to date, a total of 61 compounds involving $32 \mathrm{C}_{21}$ steroids, 13 phenols, seven triterpenoids and nine other compounds have been isolated from this plant. This minireview summarized the phytochemical and pharmacological progress on C. paniculatum to provide a reference for better understanding the effective substances of Xuchangqing.

\section{Chemical constituents}

\section{$\mathrm{C}_{21}$ steroids}

$\mathrm{C}_{21}$ steroids are the typical constituents of the genus Cynanchum. Up to date, $32 \mathrm{C}_{21}$ steroids have been isolated and identified from the roots and stems of C. paniculatum, whose structures are shown in Figure 1. According to the structure of the aglycones, the steroids in $C$. paniculatum can be classified into two types: 13,14/14,15-disecopregnane-type (1-27) in dominant and normal tetracyclic steroid type (28-32). The 13,14/14,15-disecopregnane-type steroids have a skeleton of a fused $6 / 6 / 9 / 5 / 5$ ring system with $5(6), 12(13)$ - or $5(6), 13(18)$-diene. The main substituents on aglycone are hydroxyl and methoxyl, which always present at C-2, C-3, C-7, $\mathrm{C}-17$ and $\mathrm{C}-18$ positions. The glycosyl chains predominantly at C-3 position can be monoglycosyl, diglycosyl and triglycosyl, of which 2,6-dideoxysaccharides, e.g., oleandropyranose, digitoxopyranose and cymaropyranose, are the most common glycosyls.

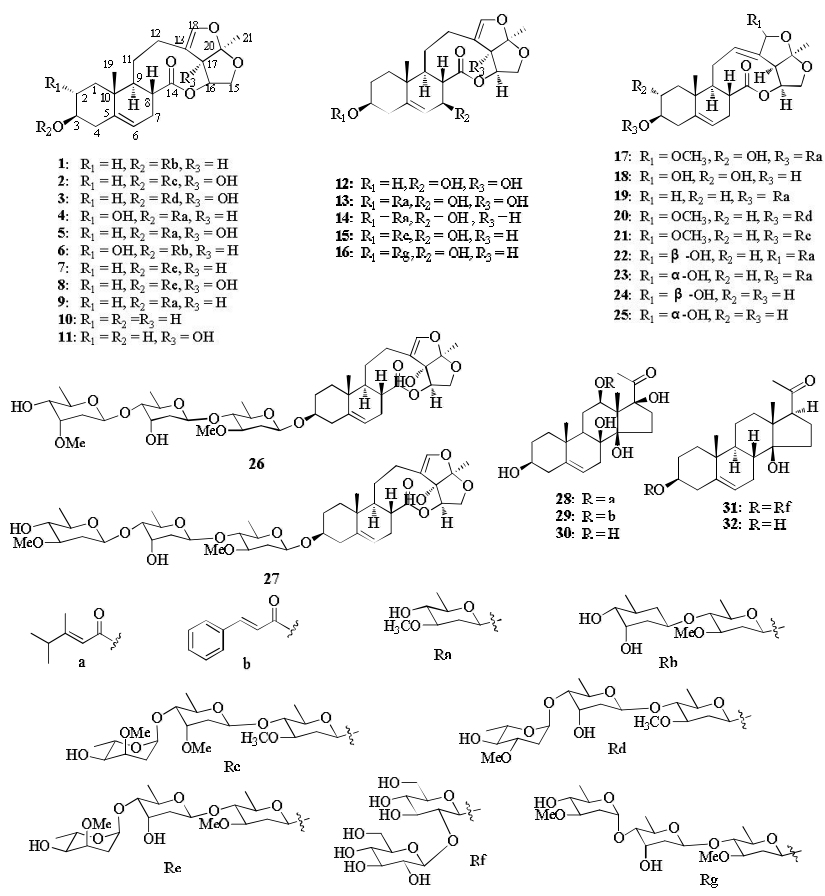

Figure $1 \quad \mathrm{C}_{21}$ steroids from C. paniculatum.

In 1986, Sugama et al. ${ }^{[4]}$ reported four 13,14/14,15-disecopregnane-type steroids, cynatratoside $B(7)$ and cynapanosides A-C (14-16), from the whole plant of $C$. paniculatum for the first time. Subsequently, researchers mainly from China and Japan performed a detailed investigation and published a se- 
ries of compounds with similar skeleton, cynapanosides $\mathrm{D}-\mathrm{F}$ $(1-3)$, glaucoside $A(4)$, neocynapanogenin $F$ 3-O- $\beta$ - $D$-oleandropyranoside (5), glaucogenin A 3-O- $\beta$ - $D$-digitoxopyranosyl$(1 \rightarrow 4)-O-\beta$ - $D$-oleandropyranoside $(6), \quad(3 \beta, 8 \beta, 9 \alpha, 16 \alpha, 17 \alpha)$ $14,16 \beta: 15,20 \alpha: 18,20 \beta$-triepoxy-16 $\beta: 17 \alpha$-dihydroxy-14-oxo- 13 , 14:14,15-disecopregna-5,13(18)-dian-3-yl $\alpha$-cymaropyranosyl$(1 \rightarrow 4)$ - $\beta$-digitoxopyransyl-( $1 \rightarrow 4)-\beta$-oleandropyranoside $(8)$, cynatratoside $A(9)$, glaucogenin $C(10)$, neocynapanogenin $F$ (11), glaucogenin $F(12)$, glaucogenin $F$ 3-O- $\beta-D$-oleandropyranoside (13), neocynapanogenin $\mathrm{H} 3-O-\beta-D$-oleandropyranoside (17), neocynapanogenin $C$ (18), cynapanoside $A$ (19), cynansides $A$ and $B(20,21)$, paniculatumosides $A$ and $B$ $(22,23)$, neocynapanogenin $B(24)$, neocynapanogenin $C(\mathbf{2 5})$, $(3 \beta, 8 \beta, 9 \alpha, 16 \alpha, 17 \alpha)-14,16 \beta: 15,20 \alpha: 18,20 \beta$-triepoxy-16 $\alpha, 17 \alpha-$ dihydroxy-14-oxo-13, 14:14,15-disecopregna-5,13(18)-dien3 -yl $\alpha$-cymaropyranosyl-( $1 \rightarrow 4)$ - $\alpha$ - digitoxopyranosyl-( $1 \rightarrow 4)-\alpha$ oleandropyranoside (26), and $(3 \beta, 8 \beta, 9 \alpha, 16 \alpha, 17 \alpha)-14,16 \beta: 15$, $20 \alpha: 18,20 \beta$-triepoxy-16 $\beta: 17 \alpha$-dihydroxy-14-oxo- 13,14:14,15disecopregna-5,13(18)-dien-3-yl $\alpha$-oleandropy- ranosyl-( $1 \rightarrow 4)$ $\alpha$-digitoxopyranosyl- $(1 \rightarrow 4)$ - $\alpha$-oleandropyran-oside $(27) .{ }^{[4-11]}$

Besides the above mentioned 13,14/14,15-diseco-pregnane-type steroids, five normal tetracyclic $\mathrm{C}_{21}$ steroids were also isolated from $C$. paniculatum, namely caudatin (28), kidjolanin (29), deacylmetaplexigenin (30), cynapanoside $\mathrm{G}$ (31) and $3 \beta, 14$-dihydroxy-14 $\beta$-pren-5-en-20-one (32). The normal $C_{21}$ steroids were also widely existed in other Asclepiadaceae plants. ${ }^{[6,7]}$

\section{Phenols}

In addition to $\mathrm{C}_{21}$ steroids, phenols mainly acetophenones are another type of characteristic constituents in C. paniculatum Phenols existing in both roots and leaves are the dominating constituents of the essential oils. Currently, a total of 13 phenols were isolated from C. paniculatum (Figure 2), which were identified as 4'-hydroxyacetophenone (33), 4'-hydroxy-3'methoxyacetophenone (34), 2'-hydroxy-5'-methoxyacetophenone (35), paeonol (36), isopaeonol (37), 2,5-dihydroxy4-methoxyacetophenone (38), 2,3-dihydroxy-4-methoxyacetophenone (39), acetoveratrone(40), 2,5-dimethoxyhydroquinone (41), vanillic acid (42), resacetophenone (43), m-acetylphenol (44) and 3,5-dimethoxyhydroquinone (45). ${ }^{[3,7,12,13]}$
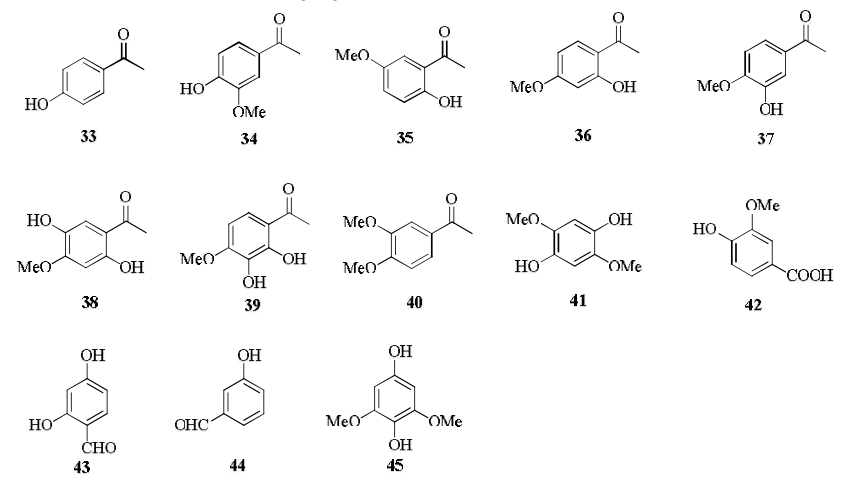

Figure 2 Phenols isolated from C. paniculatum.

\section{Volatile oils}

The whole plants of $C$. paniculatum send forth a unique fragrance due to the presence of essential oils in high content, especially in the roots. The chemical constituents of the essential oils in C. paniculatum are mainly acetophenones, represented by paeonol (36). Moreover, some other volatiles were detected by GC-MS analysis, including toluene, $p$-xylene, 1,2,4-trimethylbenzene, limonene, p-methylbenzaldehyde, 2'-hydroxyacetophenone, 1,2,4-trimethoxybenzene, methyl eugenol, $\beta$-asarone, $\alpha$-asarone, hexanal, 2 -pentylfuran, $L$-ascorbic acid-2,6-dipalmitate, hexadecanoic acid, oleic acid, octadecanoic acid, myristic acid, pentadecanoic acid, $n$-hexadecanoic acid and phytol. ${ }^{[14-17]}$

\section{Other compounds}

Some other types of compounds including triterpenoids, alkaloids, $\mathrm{C}_{29}$ steroids, and carbohydrates were also isolated from C. paniculatum. Their structures were shown in Figure 3 , and named as $\beta$-amyrin (46), oleanolic acid (47), lupeol (48), taraxasterol (49), $\alpha$-amyrin (50), ursolic acid (51), maslinic acid (52), antofine (53), 14-hydroxyantofine (54), 5-O-demethylantofine (55), $\beta$-sitosterol (56), $\beta$-daucosterol (57), ${ }^{[7]}$ methyl $2,6$-dideoxy-3-O-methyl- $\alpha$ - $D$-arabino-hexo-pyranosyl-(1 $\rightarrow 4)$ 2,6-deoxy-3-O-methyl- $\beta$ - $D$-arabino-hexopyranosyl-( $1 \rightarrow 4)$-2,6dideoxy-3-O-methyl- $\alpha$ - $D$-arabino-hexopyranoside (58), ethyl 2,6-dideoxy-3-O-methyl- $\beta$ - $D$-ribo-hexopyranosyl-( $1 \rightarrow 4)-2,6$ dideoxy-3-O-methyl- $\alpha$-L-lyxo-hexopyranoside (59), methyl 2,6dideoxy-3-O-methyl- $\alpha$ - $L$-ribo-hexopyranosyl- $(1 \rightarrow 4)-2,6$ dideoxy-3-O-methyl- $\beta$ - $D$-lyxo-hexopyranosyl-( $1 \rightarrow 4)-2,6$ dideoxy-3- O-methyl- $\alpha-D$-arabino-hexopyranoside $(60)$ and 2,6 -dideoxy-3-O-methyl- $\beta$ - $D$-ribo-hexopyranosyl- $(1 \rightarrow 4)$ 2,6-dideoxy-3-O-methyl- $\alpha$ - $D$-arabino-hexopyranosyl- $(1 \rightarrow 4)$ 2,6dideoxy-3-O-methyl- $\alpha$ - $D$-arabino-hexopyranose $(61) .{ }^{[18]}$

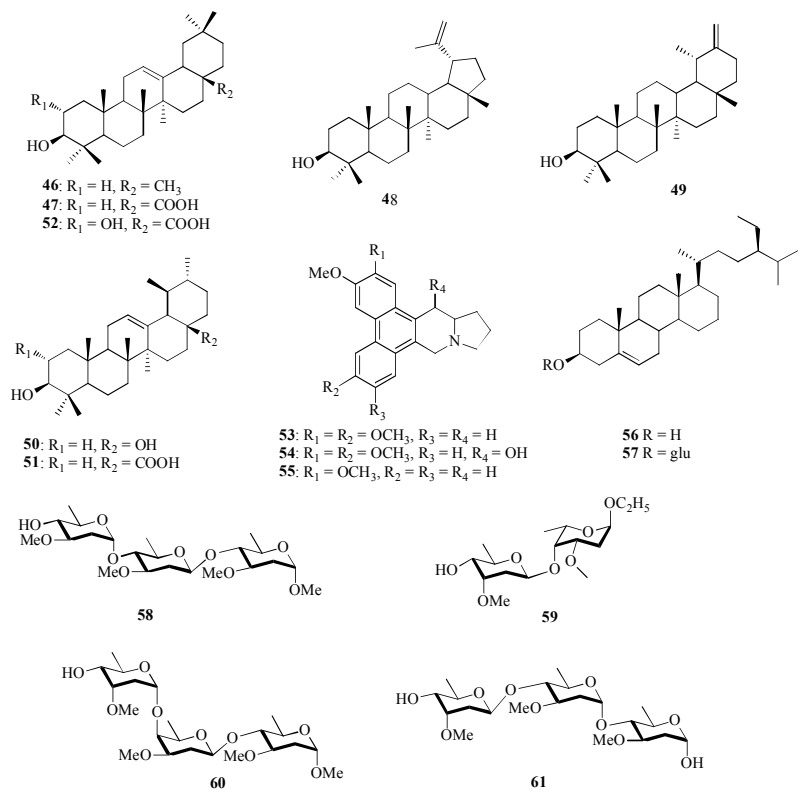

Figure 3 Other compounds from C. paniculatum.

\section{Biological activities and clinical application}

C. paniculatum as the raw material of Xuchangqing is a famous Chinese traditional medicine for the treatment of diverse diseases, such as rheumatism, snakebites, chronic bronchitis and various pains. Pharmacological study on $C$. paniculatum revealed that the crude extracts and pure compounds showed a wide range of biological activities, mainly anti-inflammatory, anti-snake venom, anti-microbial, neuroprotective and anti-cancer effects.

\section{Anti-inflammatory activity}

Wu and $\operatorname{Ren}^{[19]}$ reported that paeonol could inhibit the excessive apoptosis of osteoarthritis chondrocytes, and the mechanism was considered to be the regulation of P53 and $\mathrm{Bcl}-2$ gene expression. He et al. ${ }^{[20]}$ found that the root of $C$ paniculatum could effectively ameliorate 2,4,6-trinitrobenzenesulfonic acid (TNBS)-induced colitis in rats, possibly via altering the levels of cytokines. In addition, many investigations revealed the anti-inflammatory effect of $C$. paniculatum against pedal swelling and allergic contact dermatitis in mice. ${ }^{[21,22]}$

\section{Anti-snake venom effect}

C. paniculatum was always used for the therapeutic effect against snakebites in TCM, and thus, many investigations were 
focused on its anti-snake venom properties against poisonous snakes, involving Deinagkistrodon acutus and king cobra. Xiong et al. ${ }^{[23]}$ found that the ethanolic extract of C. paniculatum roots could completely inhibit the activity of protease and hyaluronidase in Deinagkistrodon acutus venom in vitro. Lin et al. ${ }^{[24]}$ reported that the total extract of $C$. paniculatum exhibited detoxication effects against the cardiotoxin from Naja atra venom.

\section{Anti-microbial activity}

Wen et al. ${ }^{[25]}$ reported that two steroids, cynatratoside $A$ and cynanversicoside $\mathrm{C}$, from $C$. paniculatum showed moderate activity against Ichthyophthirius multifiliis with $\mathrm{EC}_{50}$ values of $4.6 \mathrm{mg} / \mathrm{L}$ and $5.2 \mathrm{mg} / \mathrm{L}$, respectively. $\mathrm{Kim}$ et al. revealed that the ethyl acetate extract of $C$. paniculatum exhibited anti-viral activity against bovine viral diarrhea virus (BVDV) with an $\mathrm{IC}_{50}$ of $18.2 \mu \mathrm{g} / \mathrm{mL} .^{[26]}$

\section{Neuroprotective activity}

According to Weon et al. investigation, the phenolic compound 4,5-dimethoxypyrocatechol that was isolated from the $80 \%$ methanol extract of $C$. paniculatum showed neuroprotective effect on the glutamate-induced cellular oxidative death in HT22 cells. Meanwhile, this compound could also reduce the reactive oxygen species accumulation and calcium concentration by oxidative stress. ${ }^{[27]} \mathrm{Li}$ et al. ${ }^{[28]}$ reported that the ethanol extract of $C$. paniculatum could improve the survival rate of herpes simplex encephalitis (HSV)-infected mice and prevent cell apoptosis in neuron cell model and HSV infected brain tissue.

\section{Anti-cancer activity}

Xie et al. ${ }^{[29]}$ reported that the aqueous extract of $C$. paniculatum could obviously inhibit the cell proliferation of HepG-2 cells in vitro at the concentration of $30 \mathrm{~g} / \mathrm{L}$. The anti-hepatocarcinoma mechanism was suggested to be the block up of the cell division from $S$ phase to $G_{2}-M$ phase.$^{[11,30]}$ The polysaccharides in $C$. paniculatum were also revealed with prominent inhibition on the growth of mice sarcoma S180 cells, hepatoma $\mathrm{H} 22$ cells and EAC cells. ${ }^{[31]}$

\section{Conclusions and Perspectives}

C. paniculatum (Xuchangqi) is a famous Chinese traditional herb with variously clinical use, especially for its anti-inflammatory and analgesic effects. Although the previous investigation has disclosed that the total extract of $C$. paniculatum and the phenolic compound paeonol showed anti-inflammatory potency, the real active constituents are still disputed. For that paeonol is a common phenolic compounds widely present in Paeonia, Arisaema and Dioscorea plants, and exhibits diverse bioactivities. Instead, the characteristic components, 13,14/14,15-disecopregnane-type steroids, are little investigated for the anti-inflammatory property. Therefore, the future investigation on $C$. paniculatum should pay more attention on the anti-inflammatory and analgesic effects of the $C_{21}$ steroids.

\section{Acknowledgement}

This work was financially supported by the Reserve Talents of Young and Middle-aged Academic and Technical Leaders in Yunnan Province and the National Natural Science Foundation of China (No. 31870340).

\section{Author Contributions}

Following are the details of the contributions made by each of the authors for the manuscript: Dr. Liangyan Liu gathered the literatures and drafted the article, and Dr. Chang-An Geng helped in organizing the article.

\section{References}

[1] Pharmacopoeia of the People's Republic of China (Set of 1). China Pharmaceutical Science and Technology Press, Beijing, China, 2015.

[2] Jiang, X.; Sun, S.; Ren, J.; Wang, Y. Chemical Industry Times 2017, $31,37$.

[3] Han, L.; Zhou, X.; Yang, M.; Zhou, L.; Deng, X.; Wei, S.; Wang, W.; Wang, Z.; Qiao, X.; Bai, C. Molecules 2018, 23, 1194.

[4] Sugama, K.; Hayashi, K.; Mitsuhashi, H.; Kaneko, K. Chem. Pharm. Bull. 1986, 34, 4500.

[5] Li, S. L.; Tan, H.; Shen, Y. M.; Kawazoe K.; Hao, X. J. J. Nat. Prod. 2004, 67, 82.

[6] Zhao, D.; Feng, B.; Chen, S.; Chen, G.; Li, Z.; Lu X.; Sang X.; An, X.; Wang, H.; Pei, Y. Fitoterapia 2016, 113, 51.

[7] Niu, Y.; Chen, X.; Wu, Y.; Jiang, H. Q.; Zhang, X. L.; Li, E. T.; Li, Y. Y.; Zhou, H. L.; Liu, J. G.; Wang, D. Y. Biochem. Syst. Ecol. 2015, 61, 139.

[8] Gao, H.; Wang, W.; Chu, W.; Liu, K.; Liu, Y.; Liu, X. H.; Yao, H.; Gao, Q. Rev. Bras. Farmacogn. 2017, $27,54$.

[9] Zhao, D.; Wang, H. F.; Chen, G.; Li, Y. P.; Hua H. M.; Pei, Y. H. J. Asian Nat. Prod. Res. 2016, 18, 339.

[10] Huang, X.; Tan, A.; Yang, S.; Zhang, A. Y.; Zhang, H. Helv. Chim. Acta 2009, 92, 937.

[11] Dou, J.; Li, P.; Bi, Z. M.; Zhou, J. L. Chin. Chem. Lett. 2007, 18 300.

[12] Kim, M.; Yang, J.; Lee, H. J. Agric. Food Chem. 2013, 61, 7568.

[13] Weon, J. B.; Kim, C. Y.; Yang, H. J.; Ma, C. J. Arch. Pharm. Res. 2012, 35, 617

[14] Zhang, F.; Fu, S.; Xu, Q.; Zhang, X.; Xiao, H.; Liang, X. J. Essent. Oil Res. 2005, 17, 630

[15] Zhao, C.; Yang, Z. B.; Zhang, Q. J.; Zhou X,; Chen H. G.; Li, M. J. Guizhou Univ. (Nat. Sci.) 2007, 24, 407.

[16] Xu, X.; Jiang, J. J. Univ. South China (Sci. Technol.) 2011, 25, 84.

[17] Li, Y. P. Master Degree Dissertation, Shanxi University, Taiyuan, China, 2014

[18] Zhao, Y. B.; Fan, Q. S.; Xu, G. L.; Feng, Z. L.; Hao, X. J. J. Carbohydr. Chem. 2008, 27, 401.

[19] Wu, Q.; Ren, J. J. Hubei Univ. Chin. Med. 2016, 18, 11.

[20] He, H. H.; Shen, H.; Zhu, X. X.; Gu, P. Q.; Liu, Y. J.; Zhu, L.; Zheng, K. World Chin. J. Digestol. 2012, 20, 2237.

[21] Lin, L. S.; Liu, G. F.; Wang, Q. C.; Li, K. H. J. Fujian Med. Univ. 2003, 37, 188.

[22] Xu, Q. S.; Zhang, H. Y.; Li, Y. J.; Li, D. Lishizhen Med. Mater. Med. Res. 2007, 18, 1407.

[23] Xiong, Y.; Li, B.; Huang, D.; He, Q.; Yu, X. J. Ethnopharmacol. 2018, 225, 189.

[24] Lin, L.; Xu, Y.; Liu, G.; Wang, C. X.; Wang, Q. C. J. Fujian Med. Univ. 2003, 37, 301

[25] Wen, J. H.; Wang, Y. L.; Liu, Y. H.; Zhang, J. Y.; Li, Z. H. Parasitology 2017, 144, 179.

[26] Kim, W.; Oh, T. S.; Park, Y. J. Afr. J. Tradit. Complem. 2017, 14, 194.

[27] Weon, J. B.; Lee, B.; Yun, B. R.; Lee, J.; Ma, C. J. Pharmacogn Mag. 2014, 10, 161.

[28] Li, X. F.; Guo, Y. J.; Zhang, D. M.; Chen, Z.; Wei, X.; Li, Y. H.; Zhang, S. L.; Tao, J. Y.; Dong, J. H.; Mei, Y. W.; Li, L. L.; Zhao, L. Int. J. Immunopath. Ph. 2012, 25, 259.

[29] Xie, B.; Yang, Z. F.; Chen, Q. Y.; Liu, N. China Tropical Med. 2006, 6, 228.

[30] Huang, W. Master Degree Dissertation, Guangzhou University of Traditional Chinese Medicine, Guangzhou, China, 2007

[31] Zhao, L. P. China Pharm. 2011, 20, 79

Received January 9, 2019 Accepted February 21, 2019 